\title{
OS CENTROS DE REFERÊNCIA EM DIREITOS HUMANOS DA SECRETARIA DE DIREITOS HUMANOS E A INTERAÇÃO COM A TEMÁTICA MEMÓRIA E VERDADE
}

\author{
Eduardo Shigueo Fujikawa ${ }^{1}$ \\ Manuela Abreu Corradi Cruz².
}

\section{RESUMO}

A efetivação de políticas e ações voltadas para a memória, verdade e justiça de transição relativa, sobretudo, ao período de regime militar, constitui um fator importante no âmbito da afirmação da democracia, da cidadania e do fortalecimento de práticas civis e emancipatórias do Brasil. A necessidade pela reconstrução histórica em busca da superação e da retratação das violações ocorridas durante o período é fundamentada pelos avanços normativos positivados e pela concepção de estratégias e ações do governo federal para a temática. Neste contexto, os Centros de Referência em Direitos Humanos (CRDH), como ação estratégica da Secretaria de Direitos Humanos da Presidência da República (SDH/PR), emergem como importantes atores para a promoção da temática sobre o direito à memória e à verdade. O presente artigo apresenta o processo de construção do eixo estratégico de atuação dos Centros de Referência em Direitos Humanos sobre a temática a partir

\footnotetext{
${ }_{1}$ Mestre em Cooperação e Desenvolvimento Internacional pela Universidade Católica do Coração Sagrado de Milão, Itália. Foi consultor do PNUD para os Centros de Referência em Direitos Humanos da Secretaria de Direitos Humanos da Presidência da República. E-mail: eduardofujikawa@gmail.com

${ }^{2}$ Cientista política pela Universidade de Bologna, Itália é, atualmente, consultora UNESCO para os Centros de Referência em Direitos Humanos da SDH/PR.

E-mail: manuelacorradi@gmail.com
} 
dos Encontros Nacionais dos CRDH e o mapeamento das ações realizadas pelos CRDH que possibilitaram espaços de debate com a sociedade sobre as inúmeras violações de direitos humanos sofridas durante o Regime Militar. As informações apresentadas são resultantes de pesquisa bibliográfica e de coleta de dados realizada pelas consultorias prestadas pelos autores do artigo para a CoordenaçãoGeral dos Centros de Referência em Direitos Humanos da SDH/ PR, nos anos de 2013 e 2014.

Palavras-chave: Direito à Memória e Verdade. Direitos Humanos. Políticas Públicas.

\begin{abstract}
The effectiveness of policies addressed to the right to memory, transitional justice and the truth, especially concerning the military dictatorial period in Brazil, is a key factor for the reinforcement of democracy and citizenship and the straightening of civic and emancipatory practices in the country. The need of historical reconstruction which includes the surpass and withdrawal of human rights violations taken place during the period, is based on the normative advancements and the conception of new strategies and policies of federal government for theseissues. In this context, the Reference Centers on Human Rights, as a strategic action of the Secretariat for Human Rights of the Presidency of the Republic, emerge as important actors for the promotion of the right to memory and the truth. This article presents the building process of the strategic position of the Reference Centers on Human Rights for these subjects from the discussions in the National Gatherings of the Reference Centers as well and the mapping of their activities that contributed for the dialogue and debate about the several human rights violations that happened during the dictatorial military regime. The data presented result from bibliography research and data collection during consultancy work of the authors for the General Coordination of the Reference Centers on Human Rights in 2013 and 2014.
\end{abstract}

Keywords: Human Rights. Right to Memory and the Truth. Public Policies.

\title{
Introdução
}

Os Centros de Referência em Direitos Humanos, executados em parceria com a Secretaria de Direitos Humanos da Presidência da República (SDH/PR), representam uma importante ação estratégica 
realizada nos estados e municípios com o objetivo de promover e fortalecer uma cultura em direitos humanos, tendo como pressuposto a atuação articulada em rede, com diferentes atores estratégicos e as diretrizes do Programa Nacional de Direitos Humanos (PNDH-3). Atualmente, a rede de atuação conta com 32 Centros de Referência em Direitos Humanos implantados ${ }^{3}$, com previsão de expansão para todas as capitais federais.

A ação Centro de Referência em Direitos Humanos (CRDH) foi implantada em 2010, com o objetivo de abranger todas as temáticas de direitos humanos para promover e executar ações como: orientação, informação, capacitação e formação; disseminação e produção de conhecimentos em direitos humanos, para todo e qualquer público, executadas por diferentes parceiros, sendo eles Governos de Estado, Prefeituras, Organizações Não Governamentais e Instituições de Ensino Superior.

A característica de ampliação temática é um dos fatores estratégicos da concepção da ação $\mathrm{CRDH}$, uma vez que respeita e consolida os princípios da transversalidade e interdependência dos direitos humanos e possibilita uma atuação intersetorial e horizontal.

Nesse sentido, a temática do direito à Memória e à Verdade passa, também, a ser pauta prioritária das ações dos Centros de Referência em Direitos Humanos, sobretudo de capacitação e formação. Esta agenda de trabalho integra as diretrizes e as diferentes ações realizadas pela Secretaria de Direitos Humanos da Presidência da República (SDH/PR), fortalecidas pela instituição e consolidação da Comissão Especial sobre Mortos e Desaparecidos Políticos (CEMDP), pela Comissão Nacional da Verdade (CNV) e pelas ações realizadas em ocasião dos 50 anos do Golpe Militar, completados em 31 de março de 2014.

\footnotetext{
${ }_{3}^{3}$ Região Norte: CRDH Palmas/TO; Região Nordeste: CRDH Fortaleza/CE, CRDH Teresina/ PI, CRDH Mossoró/RN, CRDH João Pessoa/PB, CRDH Caruaru/PE, CRDH Aracaju/SE, CRDH Maceió/AL, CRDH Salvador/BA (dois) e CRDH Jequié; Região Centro-Oeste: CRDH Campo Grande/MS, CRDH Cuiabá/MT e CRDH Cáceres; Região Sudeste: CRDH Betim/ MG, CRDH Belo Horizonte/MG, CRDH Juiz de Fora/MG, CRDH São Paulo/SP, CRDH Rio de Janeiro/RJ, CRDH São José do Meriti, CRDH Petrópolis/RJ e CRDHVitória/ES; Região Sul: CRDH Pinhais/PR, CRDH Curitiba/PR, CRDH Florianópolis/SC, CRDH Chapecó/ SC, CRDH Porto Alegre/RS (dois), CRDH Sapucaia do Sul/RS, CRDH Novo Hamburgo/RS, CRDH São Leopoldo/RS e CRDH Rio Grande/RS.
} 
Diante desse cenário, este artigo tem como objetivo apresentar a ação CRDH como importante instrumento de fomento e discussão sobre a temática do direito à Memória e à Verdade, o seu processo de interação com a temática e o mapeamento das ações realizadas nas localidades onde estão inseridos, possibilitando espaços de debate com a sociedade sobre as violações de direitos humanos sofridas durante o Regime Militar.

A metodologia de trabalho utilizada contou com a sistematização das ações coletadas pelas consultorias prestadas para a Coordenação Geral dos Centros de Referência em Direitos Humanos da SDH/PR, nos anos de 2013 e 2014. O mapeamento das ações realizadas abrangeu o período de janeiro a julho de $2014^{4}$, não inclusas as atividades planejadas e previstas para realização posterior a julho de 2014. Ressaltase que a metodologia para a escolha do período de análise converge com a estratégia de intensificação de atuação da SDH/PR para com a temática e, consequentemente, da rede dos $\mathrm{CRDH}$ em ocasião dos 50 anos do golpe militar. O conjunto de ações apresentado neste artigo não contempla todas as ações realizadas pelos $\mathrm{CRDH}$ nas suas localidades, uma vez que alguns Centros de Referência não responderam às demandas da consultoria eoutros se encontravam em fase de implantação, recém inauguração ou encerramento do convênio ${ }^{5}$. Outro aspecto a ser considerado é a inclusão de ações realizadas por Centros de Referência em Direitos Humanos que tiveram seus convênios encerrados com a $\mathrm{SDH} / \mathrm{PR}$, mas que realizaram ações no âmbito da temática quando ainda possuíam os convênios vigentes.

\section{Temática Memória e Verdade: breves considerações}

A afirmação de uma cultura de respeito aos direitos humanos está diretamente ligada à mobilização e participação de um conjunto

\footnotetext{
${ }^{4}$ Somente o CRDH Petrópolis/RJ foi incluído com ações mapeadas sobre a temática no período de 2012 a julho/2014. A escolha de inserir as ações anteriores a 2014 realizadas por este Centro deve-se ao histórico de atuação do Centro de Defesa de Direitos Humanos, organização não governamental executora da ação $\mathrm{CRDH}$, bem como de fatores relativos à história local. Estes dois fatores determinaram uma coleta de dados mais direcionada por parte da consultoria em relação aos demais Centros de Referência, orientada pela Coordenação Geral.

${ }^{5}$ Para estes casos, a consultoria não solicitou informações.
} 
de atores, dentre eles: Estados, organizações não governamentais, sociedade civil, organizações intergovernamentais, tribunais internacionais e outros, sendo que esta arquitetura deve estar articulada e as políticas consolidadas para que haja efetividade dos direitos. No Brasil, o direito à Memória, à Verdade e à Justiça Transicional representa um tema complexo, que engloba uma série de violações aos direitos humanos e que, ainda, encontra limitações no âmbito da realização efetiva de ações políticas que busquem a revelação da verdade, a reparação das vítimas, o julgamento e punição dos envolvidos como também a revisão das leis.

A compreensão da temática perpassa por fatores históricos, no processo de investigação de como e porque os fatos ocorreram, quem estava envolvido e suas responsabilidades pelo processo de envolvimento e interlocução social, denominado como uma compreensão moral, política e educativa, que engloba ações voltadas para a consolidação da democracia e a efetividade de uma justiça de transição (LEAL, 2012). O sucesso da compreensão desses fatores irá colaborar para a promoção de uma justiça transicional e a capacidade da sociedade e Estado promover uma cultura de respeito aos direitos humanos.

Segundo Zyl (2005, p. 32), a justiça de transição se caracteriza como o "esforço para a construção da paz sustentável após um período de conflito, violência em massa ou violação sistemática dos direitos humanos" e engloba a revelação da verdade dos crimes ocorridos, a reparação das vítimas, o processo de seus perpetradores, a reforma das instituições perpetradoras de abuso e a promoção da reconciliação entre a sociedade e o Estado. No âmbito da justiça, a realização dos julgamentos dos perpetradores que cometeram tais violações é um fator importante no sentido de prevenir outras situações similares, além de impulsionar o processo de reformas institucionais e proporcionar o que Zyl (2005, p. 34) define como "consolo às vítimas". Ainda segundo Zyl, a busca pela verdade oficial, deve envolver os governos, perpetradores e a sociedade de modo a reconhecer as violações aos direitos humanos sofridas e as injustiças provocadas pelas mesmas, sensibilizar e constituir 
uma memória individual e coletiva ${ }^{6}$ (p. 35). A reparação a ser realizada pelo Estado, prevista pelo direito internacional, incluem, por exemplo, pagamentos compensatórios, pensões bem como assistência psicológica e medidas simbólicas, como a construção de monumentos e memoriais.

Assim, de acordo com os inúmeros casos de violação dos direitos humanos, a efetivação de políticas e ações voltadas para a memória, verdade e justiça de transição passa a se constituir fator importante no âmbito da democratização, da cidadania e do fortalecimento de práticas civis e emancipatórias. A temática deve ser considerada em um constante elo de conexão do passado e presente, em uma reconstrução histórica que visa à superação e a retratação do que ocorreu no período.

Para muitos pensadores e estudiosos é importante compreender a temática como uma política pública, que deve buscar responsabilizar os perpetradores das violências naquele período, de modo a resgatar a memória sobre o ocorrido e estabelecer a verdade sobre os fatos (LEMOS; LEAL, 2012). A partir da identificação do período de conflito, violência em massa ou violação sistêmica dos direitos humanos, é possível apresentar os caminhos trilhados pelo Estado no sentido de estabelecer uma verdade oficial dos fatos, constituírem uma memória coletiva e individual e consolidar os princípios democráticos e emancipatórios (ZYL, 2005).

No âmbito da história brasileira, a temática está relacionada à ditadura militar, época política que vigeu de 1964 a 1985, durante a qual foram cassados direitos civis e políticos e realizados atos de tortura, desaparecimentos e mortes de pessoas que se opunham ao regime e lutavam pelo retorno da democracia.

A temática passa a ser pautada pelo Estado brasileiro a partir do processo de redemocratização, com a Constituição de 1988, que no seu artigo $4^{\circ}$, afirma que a República Federativa do Brasil se rege nos princípios internacionais, "com a prevalência dos direitos humanos" e garante, no seu artigo $5^{\circ}$, a inviolabilidade, entre outras, da liberdade, garantindo que "ninguém será submetido à tortura nem a tratamento desumano ou degradante" (BRASIL, 1988).

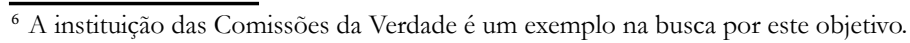


A atenção progressiva do Estado Brasileiro é reafirmada pela incorporação de alguns importantes tratados internacionais, sendo o marco inicial desse processo a ratificação da Convenção contra Tortura e Outros Tratamentos Cruéis, Desumanos ou Degradantes, em 1989 (PIOVESAN, 2014, p. 58). Vale citar ainda o Pacto Internacional dos Direitos Civis e Políticos, aprovado pela Assembleia das Nações Unidas em 1976 e sancionado pelo Brasil em 1992 e a Convenção Sobre Direitos Humanos, conhecida como o Pacto de São José da Costa Rica, de 22 de setembro de 1969, também sancionada pelo Brasil em 1992. No âmbito da jurisdição interna, a Lei 9.140 de 04 de dezembro de $1995^{7}$ reconheceu a responsabilidade do Estado brasileiro pela morte de dezenasde pessoas durante o regime militar e previu a criação da Comissão Especial sobre Mortos e Desaparecidos Políticos (CEMDP) em $1995^{8}$.

No plano mais recente, destacam-se ainda os recorrentes debates sobre a necessidade de revisão da Lei da Anistia de $1979^{\circ}$ e a instauração da Comissão Nacional da Verdade (CNV) em 16 de maio de $2012^{10}$, como importante instrumento para a efetivação do direito à verdade e à memória, com o objetivo de apurar graves violações de direitos humanos ocorridas no período de 18 de setembro de 1946 e 05 de outubro de $1988^{11}$.

\footnotetext{
${ }_{7}$ A Lei 9.140/1995 foi alterada em 2004 pela Lei 10.875 e atribuiu a CEMDP outras competências para além daquelas já previstas.

8 A Comissão Especial sobre Mortos e Desaparecidos é atualmente é vinculada à Secretaria de Direitos Humanos.

${ }^{9}$ A interpretação habitual dada à Lei é a abrangência do artigo $1^{\circ}$, uma vez que segundo esta linha de pensamento foi anistiada, para além dos presos políticos, os agentes do Estado que perseguiram e cometeram violações de direitos humanos. Dessa forma, a grande questão sobre a revisão desta Lei é a garantia de que seja explicitado no seu texto que a mesma não deve ser aplicada àqueles que comentaram violações de direitos humanos. Vale citar, ainda no âmbito da Lei de Anistia, a instalação da Comissão de Anistia, em 28 de agosto de 2001, criada pela Medida Provisória 2.151, que tem como objetivo analisar os pedidos de indenização formulados por pessoas que foram impedidas de exercer atividades econômicas por motivação, exclusivamente, política, do período de 18 de setembro de 1946 a 05 de outubro de 1988. Sobre as ações realizadas por esta Comissão, destacam-se as Caravanas da Anistia que realizam sessões públicas itinerantes de apreciação de requerimentos de anistia política acompanhadas por atividades educativas e culturais.

${ }^{10}$ A Comissão Nacional da Verdade foi instituída pela lei 12.528 de 18 de novembro de 2011 e instalada em 16 de maio de 2012.

${ }^{11}$ A CNV criada em 2011 tem até o dia 16 de dezembro de 2014 para concluir seus trabalhos e apresentar o relatório circunstanciado contendo as atividades realizadas, os fatos examinados, suas conclusões e recomendações.
} 
Outro avanço diz respeito à Lei 11.111 de 05 de maio de 2005, que previa a prorrogação indefinida do prazo de sigilo de documentos públicos classificados como de alto grau de confidencialidade. A Lei foi revogada pela Lei $12.527^{12}$, de 18 de novembro de 2011, conhecida como Lei de Acesso a Informação que permite acesso público, com fins de pesquisa e história, de documentos, regulamentando o acesso às informações.

Leal ainda destaca outras ações realizadas no âmbito da temática durante os anos 90 como:

A extinção do Serviço Nacional de Informações - SNI; a criação do Ministério da Defesa, adequando os comandos militares ao civil; a extinção dos DOI-CODI e DOPS; a criação da Secretaria Especial de Direitos Humanos; a criação do Centro de Referência das Lutas Políticas no Brasil-Memórias Reveladas, coordenado pelo Arquivo Nacional da Casa Civil da Presidência da República, para a organização e difusão de documentos, de modo a produzir estudos e pesquisas sobre o regime político de 1964 a 1985, dentre outros (LEAL, 2012, p. 29).

Outras ações importantes no âmbito da realização e efetivação de políticas para a temática vieram com a terceira versão do Programa Nacional de Direitos Humanos (PNDH-3), lançado em 2009, que apresentou ações efetivas relativas à temática da Memória e Verdade, sendo um dos seus eixos orientadores, o Eixo VI denominado "Direito à Memória e à Verdade", composto por três diretrizes e três objetivos estratégicos de atuação, sendo a temática considerada como um dos princípios históricos dos direitos humanos. No âmbito do PNDH3, a Secretaria de Direitos Humanos da Presidência da República ${ }^{13}$ é responsável direta ou indiretamente e em parceria com outros Ministérios, por todas as ações programáticas previstas pelos objetivos estratégicos relativos à temática. Entre as ações implementadas pela SDH/PR destacam-se aquelas realizadas pela Coordenação Geral do Projeto Direito à Memória e à Verdade, pela Comissão Especial de

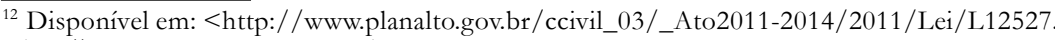
htm\#art46>. Acesso em: 29 jul. 2014.

${ }^{13}$ No texto do PNDH-3 é citada a então Secretaria Especial de Direitos Humanos, hoje Secretaria de Direitos Humanos da Presidência da República.
} 
Mortos e Desaparecidos Políticos e pelos Centros de Referência em Direitos Humanos.

Em particular, a ação Centro de Referência em Direitos Humanos (CRDH) possui papel estratégico de atuaçãonos estados e municípios na implementação de atividades voltadas para asdiferentes temáticas de direitos humanos, inclusive daquelas relativas à memória e à verdade. $\mathrm{O}$ fortalecimento da atuação dos CRDH para com a temática percorreu um processo de amadurecimento que culminou na realização de variadas ações de promoção e sensibilização nos diferentes contextos locais.

\section{Mapeamento das ações dos Centros de Referência em Direitos Humanos em interação com a temática Memória e Verdade}

O tema da Memória e Verdade integra juntamente às demais temáticas de direitos humanos, a agenda de trabalho dos Centros de Referência em Direitos Humanos. Como espaço de participação, interação e discussão destastemáticas, a Coordenação Geral dos CRDH realiza anualmente os Encontros Nacionais dos Centros de Referência em Direitos Humanos ${ }^{14}$ que, desde a sua concepção, têm como objetivo possibilitar uma aproximação da Secretaria de Direitos Humanos da Presidência da República com as equipes, possibilitar a troca de experiências entre os participantes e abrir um espaço para debater diversas temáticas de direitos humanos.

Durante o $3^{\circ}$ Encontro Nacional dos CRDH foi construído um calendário anual, com datas emblemáticas sobre direitos humanos a serem lembradas por meio de ações realizadas pelas equipes de todos os Centros de Referência nos estados e municípios, contemplando a temática Memória e Verdade, no dia 31 de março, de modo a possibilitar a reflexão sobre o tema na data em que o Golpe Militar foi efetivado.

\footnotetext{
${ }^{14}$ Os Encontros Nacionais dos Centros de Referência em Direitos Humanos acontecem duas vezes por ano, em Brasília, e conta com a participação de representantes das equipes, sendo esta uma etapa prevista pelos Planos de Trabalho de todos os CRDH. O $1^{\circ}$ Encontro Nacional aconteceu nos dias 26 e 27 de março de 2012; o $2^{\circ}$ Encontro Nacional aconteceu de 12 a 14 de novembro de 2012, o $3^{\circ}$ Encontro Nacional aconteceu de 23 a 26 de abril de 2013, o $4^{\circ}$ Encontro Nacional aconteceu em dezembro de 2013 durante o Fórum Mundial de Direitos Humanos, o $5^{\circ}$ Encontro Nacional aconteceu de 24 a 26 de fevereiro de 2014 e o $6^{\circ}$ Encontro Nacional aconteceu nos dias 06, 07 e 08 de agosto de 2014.
} 
No $4^{\circ}$ Encontro Nacional realizado em Brasília, durante o Fórum Mundial de Direitos Humanos, a Coordenação-Geral dos $\mathrm{CRDH}$ iniciou o debate sobre Memória e Verdade, temática eixo para o ano de 2014. Esta decisão se deu pela necessidade de fortalecimento da pauta por meio de ações continuadas, em ocasião dos 50 anos de resistência ao Golpe Militar, de modo a fomentar o debate com os diversos atores estratégicos da rede e com a sociedade civil. Esta proposta se concretizou durante o $5^{\circ}$ Encontro Nacional dos CRDH e teve a participação de representantes de aproximadamente, 20 Centros de Referência em Direitos Humanos. A programação contou com dois momentos específicos para a temática Memória e Verdade, sendo eles: Mesa 01: Memória e Verdade - 50 anos de resistência ao golpe de 1964; Grupo de Trabalho: Reunião com os CRDH sobre a temática e Ato de Lançamento do Fórum Nacional pela Democracia - 50 anos de resistência ${ }^{15}$.

A partir da construção desta agenda realizada durante os Encontros Nacionais, a atuação dos Centros para com a temática aconteceu em diferentes espaços e formatos, sejam na articulação e participação de reuniões em Comissões ou Comitês, na participação e promoção de campanhas, atos públicos, notas públicas, debates, palestras e seminários. A realização destas ações foi definida autonomamente pelos Centros e suas equipes, conforme o planejamento e o contexto local. O quadro a seguir apresenta, de forma sintética, as ações realizadas pela rede dos Centros de Referência em Direitos Humanos para temáticas relacionadas à Memória e Verdade ${ }^{16}$ :

\footnotetext{
15 Esta atividade foi inserida como atividade complementar ao Encontro, com participação facultativa. O Ato aconteceu na sede da OAB Nacional, em Brasília.

${ }^{16}$ A metodologia para a coleta dos dados apresentados é detalhada na introdução deste artigo.
} 


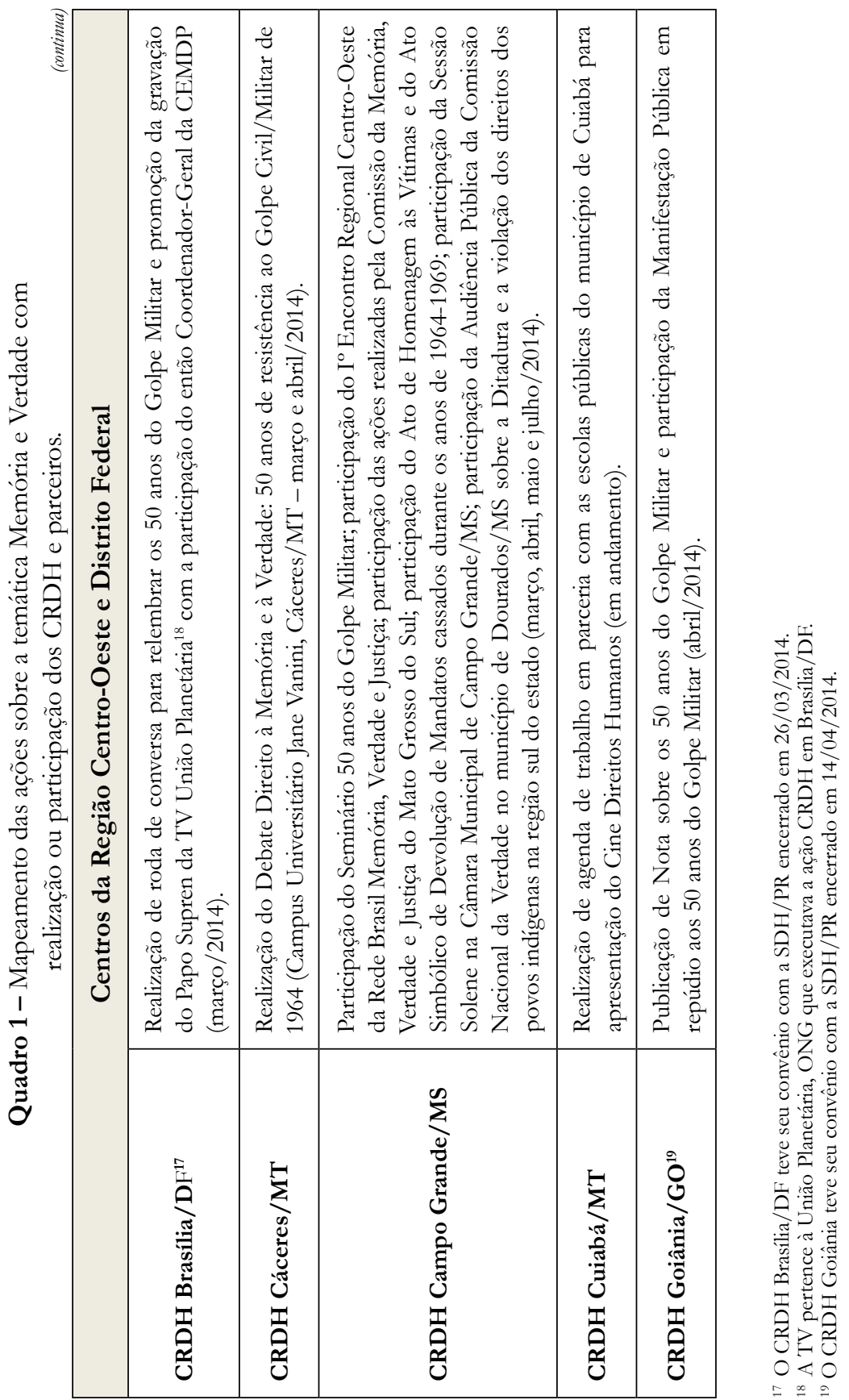




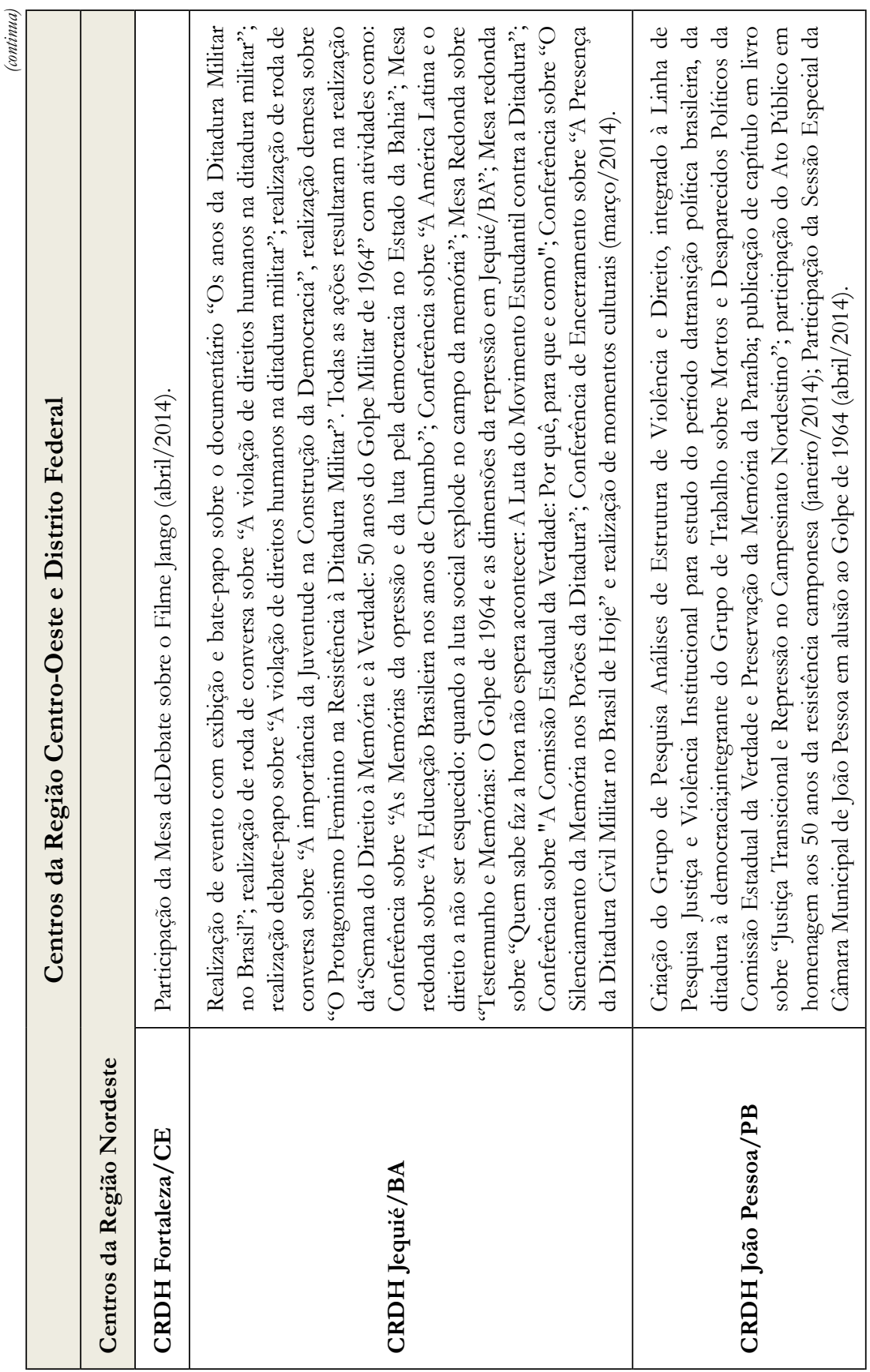




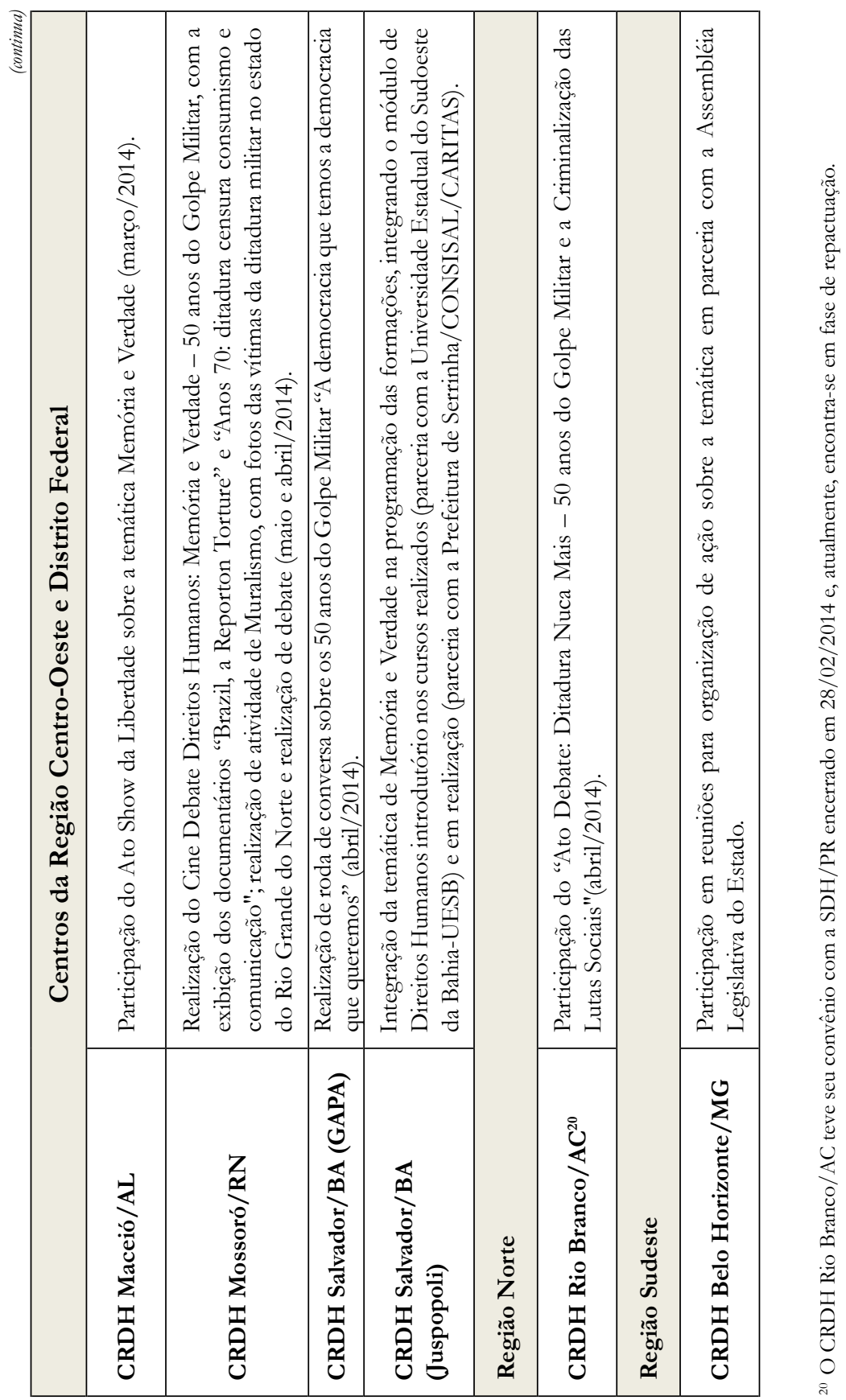




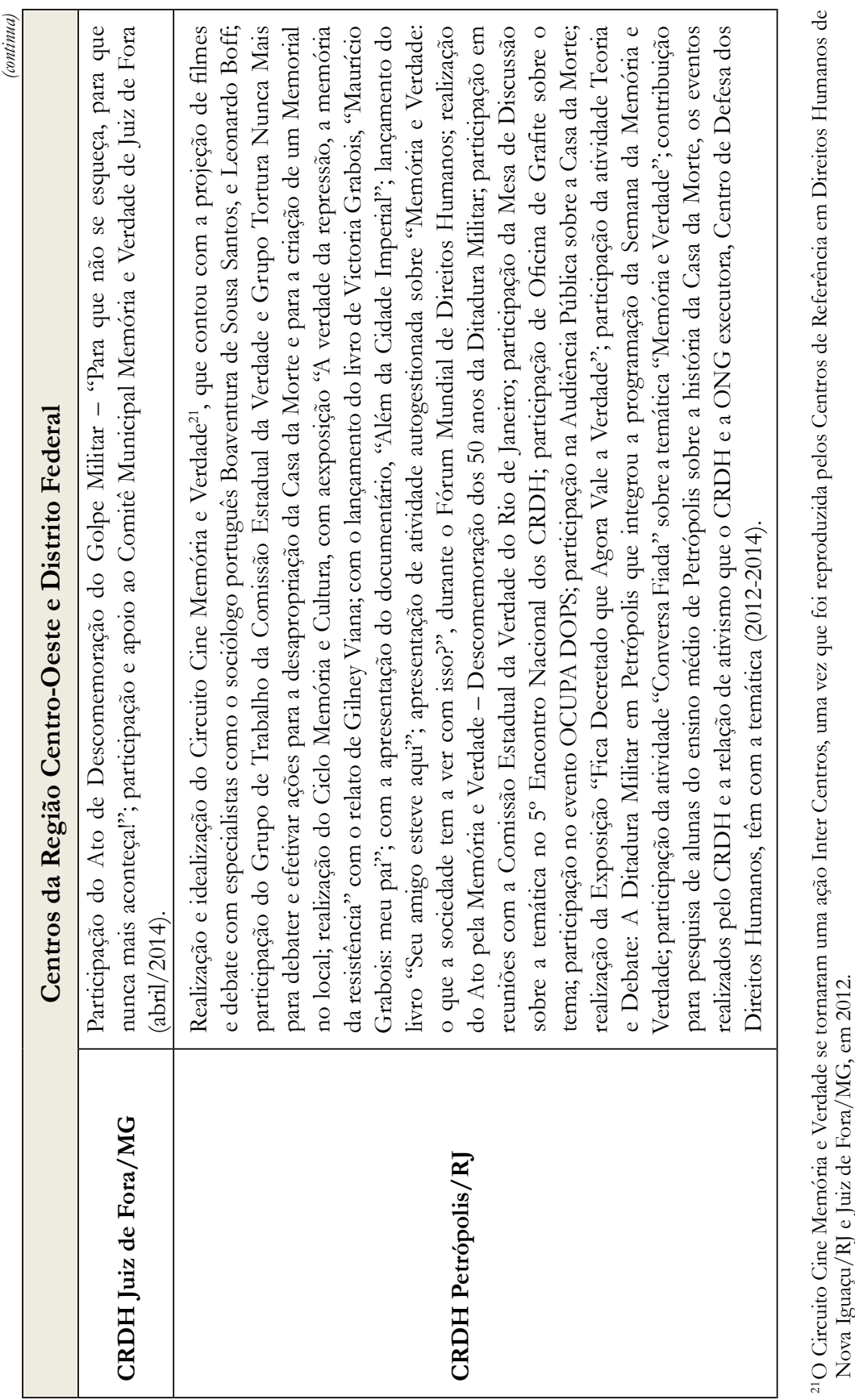




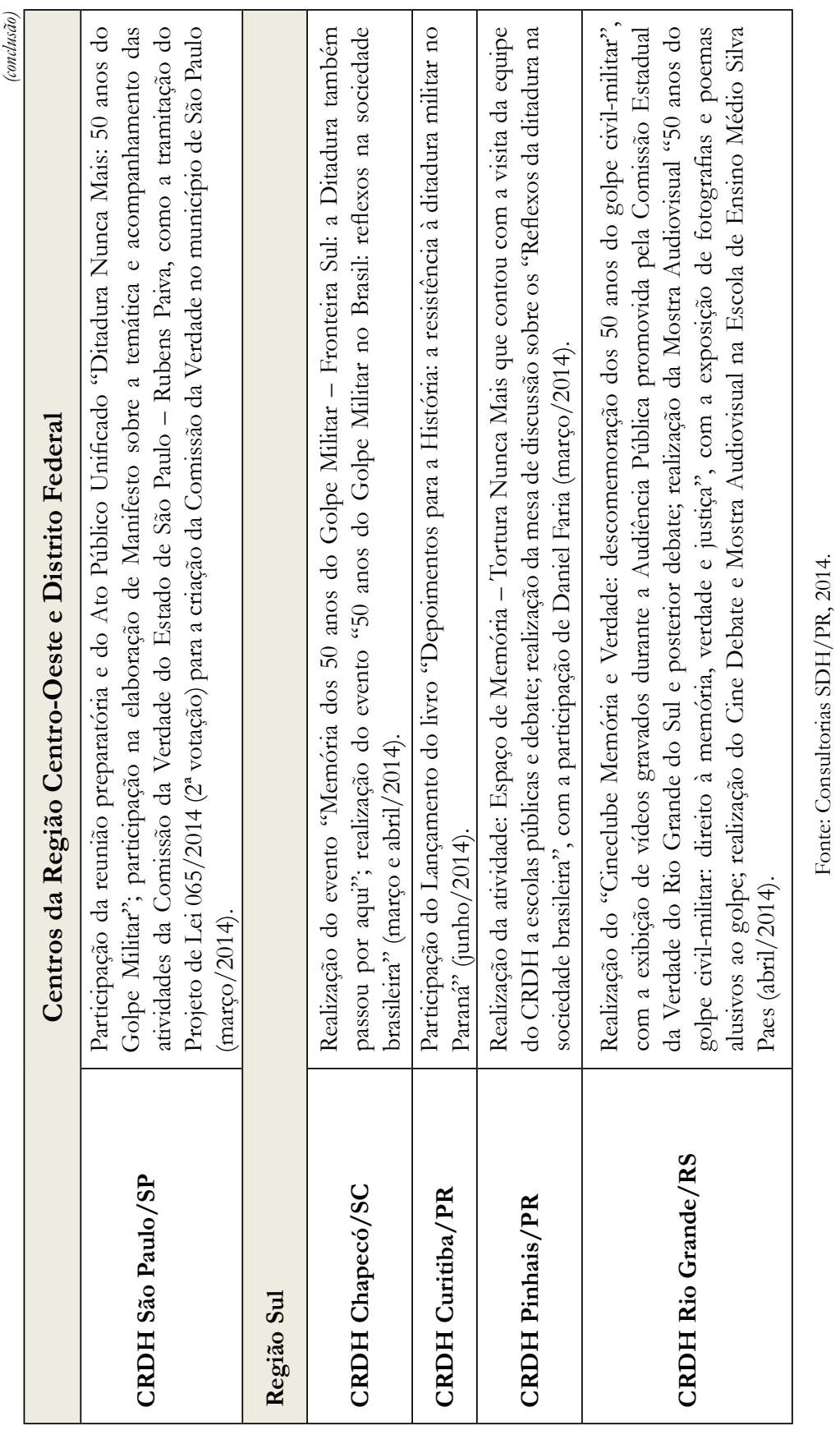


Verifica-se que os $\mathrm{CRDH}$ realizaram um conjunto diversificado de ações com o fim de promover o debate e conhecimento sobre a temática no contexto local, segundo as diretrizes previstas pelo PNDH3 e as estratégias de atuação incentivadas pela Secretaria de Direitos Humanos da Presidência da República. As ações foram desenvolvidas com diferentes abordagens, como atividades de sensibilização, de formação, de fomento à cultura, de articulação em rede, de representação política e de produção de conhecimento.

Como é possível observar, alguns Centros de Referência em Direitos Humanos apresentaram uma atuação mais ampla e diversificada sobre a temática. Este aspecto está relacionado, sobretudo, ao tempo de execução da ação $\mathrm{CRDH}$, ao histórico institucional do parceiro executor da ação CRDH e aos fatores históricos, culturais e políticos determinados pelos contextos locais. Verifica-se, por exemplo, a marcante atuação do CRDH Petrópolis, motivada seja pelo histórico de atuação do Centro de Defesa dos Direitos Humanos de Petrópolis, Organização Não Governamental executora da ação CRDH, que pelos fatores históricos, culturais e políticos, como a existência da Casa da Morte na localidade. Outros exemplos são a atuação do Centro de Jequié/BA, no âmbito da educação em direitos humanos; a pesquisa promovida pelo $\mathrm{CRDH}$ João Pessoa/PB na linha de pesquisa "Justiça e Violência Institucional" e ainda as ações de sensibilização realizadas pelos CRDH de Chapecó/ SC, Mossoró/RN e outros Centros.

\section{Considerações Finais}

Constata-se que a temática do Direito à Memória e à Verdade se fortaleceu nos últimos dez anos, por meio da incorporação de normas e da realização de ações e políticas que possibilitaram sua maior visibilidade e, consequentemente, a sua discussão nos diversos segmentos da sociedade. A importância de uma investigação dos fatos, da reforma das instituições, da punição dos responsáveis pelas violações, da reparação das vítimas e familiares que sofreram violações de direitos 
durante o regime militar, são fatores imprescindíveis para a construção de uma memória coletiva e individual, bem como para o fortalecimento da democracia e da cultura de respeito aos direitos humanos.

Neste cenário, os Centros de Referência em Direitos Humanos da $\mathrm{SDH} / \mathrm{PR}$ se destacam como atores estratégicos desta rede de mobilização e promoção da temática, com a participação ativa em Comissões ou Comitês locais, em Atos e Audiências Públicas, com a realização de atividades como Cine Debates, Cine Circuito, Roda de Conversa, Seminários, Palestras e outras atividades. Observa-se que grande número dos Centros de Referência, atualmente implantados, participou ou promoveu ações para o debate, disseminação e fortalecimento da matéria nos seus diversos contextos locais. Além disso, muitas das ações tiveram como público alvo: adolescentes e jovens de escolas públicas ou de universidades, sendo este um público estratégico para o debate e divulgação do tema Memória, Verdade e Justiça, uma vez que se destaca a carência do estudo da matéria para as novas gerações.

Por fim, com o estudo dos marcos legal e bibliografias referenciais sobre a temática Memória, Verdade e Justiça de Transição é possível observar como a matéria é conceituada como uma questão de direitos humanos e, portanto, como é fundamental que a mesma seja pautada de maneira transversal e interdependente, exigindo esforços de diversos atores e parceiros para um real avanço da política e efetivação dos direitos.

\section{Referências}

BRASIL. Constituição Federal de 1988. Título II, Dos Direitos e Garantias Fundamentais Capítulo Idos Direitos e Deveres Individuais e Coletivos. Disponível em: <http://www.senado.gov.br/legislacao/const/con1988/ con1988_05.10.1988/art_5_.shtm>. Acesso em: 25 jul. 2014.

BRASIL. Secretaria de Direitos Humanos da Presidência da República. Programa Nacional de Direitos Humanos (PNDH-3). Brasília: SDH/PR, 2010. 
LEAL, R.G. A memória como direito fundamental civil e político: qual o caminho brasileiro? In: LEAL, R. G. (Org.). Verdade, memória e justiça: um debate necessário. Santa Cruz do Sul: EDUNISC, 2012.

LEMOS, M. D. T.; LEAL, M. C. H. O controle jurisdicional de políticas públicas no âmbito da verdade, justiça e reconciliação: um caminho entre o ativismo e a efetiva proteção dos direitos humanos. In: LEAL, R. G. (Org.). Verdade, memória e justiça: um debate necessário. Santa Cruz do Sul: EDUNISC, 2012.

PIOVESAN, Flávia. Temas de direitos humanos. 7. ed. São Paulo: Saraiva, 2014.

ZYL, P. V. Promovendo a justiça transicional em sociedades pósconflito. Revista Anistia, Politica e Justiça de Transição, Brasília: Ministério da Justiça, 2009. Disponível em: <http://www.portalmemoriasreveladas. arquivonacional.gov.br/media/2009RevistaAnistia01.pdf>. Acesso em: 01 ago. 2014. 